\title{
INFÂNCIA, MÍDIAS E APRENDIZAGEM: AUTODIDAXIA E COLABORAÇÃO
}

\author{
Maria Luiza Belloni* \\ Nilza Godoy Gomes ${ }^{* *}$
}

RESUMO: A interação entre pares e com adultos, em situações favoráveis e inovadoras de aprendizagem e com uso pedagógico apropriado das Tecnologias de Informação e Comunicação (TIC), pode levar as crianças a desenvolverem comportamentos colaborativos e autônomos de aprendizagem, benéficos para seu desenvolvimento intelectual e sócio-afetivo. Nossa hipótese é de que ambientes de aprendizagem computacionais tendem a ser eficazes para esta aprendizagem, pois possibilitam a mediação entre o sujeito e o objeto do conhecimento a ser construído, conforme sugerem os aportes das teorias construtivista e sócio-interacionista. $\mathrm{O}$ objetivo de nossa pesquisa é compreender como ocorrem estes "novos modos de aprender" que já vêm se desenvolvendo, à revelia da escola e, de modo geral, ignorados por professores e especialistas, desde que as crianças começaram a aceder à televisão e aos videogames e se amplificaram e complexificaram com o acesso e uso lúdico do computador e da internet.

Palavras-chave: TIC e aprendizagem. Autodidaxia. Aprendizagem colaborativa e cooperativa.

CHILDHOOD, MEDIAS AND LEARNING: SELF-TEACHING AND COLLABORATION

ABSTRACT: Interaction among peers and with adults in favorable and innovative learning situations and with pedagogy suitable to Information and Communication Technologies can lead children to

* Doutora em Ciências da Educação e professora aposentada da Universidade Federal de Santa Catarina (UfSC). E-mail: malu@ced.ufsc.br

** Mestre em Educação, pedagoga do Laboratório de Novas Tecnologias (LANTEC/UfSC) e integrante da equipe da Coordenação Pedagógica EAD-Licenciaturas da UFSC. E-mail: nilza@ced.ufsc.br

Educ. Soc., Campinas, vol. 29, n. 104 - Especial, p. 717-746, out. 2008

Disponível em <http://www.cedes.unicamp.br> 
develop collaborative and autonomous learning behavior that is beneficial for their intellectual and socio-emotional development. Our hypothesis is that learning environments with computers tend to be effective for this type of learning, because they allow mediation between the subject and object of knowledge to be built, as suggested by constructivist and socio-interactionist theories. The object of our study is to learn how these "new modes of learning" that have already been developing take place independently from the school. In general, they are ignored by teachers and specialists, given that children begin to yield to television and videogames and broaden and complexify their activity with access to and playful use of computers and the Internet.

Key words: Information and communication technology and learning.

Self-teaching. Collaborative and cooperative learning.

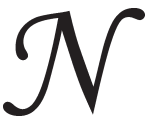

a passagem do milênio, as sociedades ocidentais centrais e periféricas vivem transformações culturais e sociais de grande importância, entre as quais o acelerado avanço técnico e científico aparece com maior visibilidade. Neste novo contexto de alta tecnologia e crescente globalização da economia e da cultura, a socialização das novas geraçóes levanta questões inéditas para todas as esferas da sociedade, entre as quais nos interessa especialmente aquelas relacionadas com os novos modos de perceber, de interagir e de aprender desenvolvidos pelas crianças e adolescentes em suas relações com as mídias novas e antigas.

Para o campo das ciências humanas, e da educação em particular, é importante ressaltar este novo desafio. No bojo daquelas mudanças, surge um novo sujeito: a criança que se apropria "naturalmente" das tecnologias de informação e comunicação, para quem a televisão e o computador fazem parte do meio-ambiente, de seu universo de socialização, do mesmo modo "natural" que o peixinho do aquário. Evidentemente, este processo de formação do ser social e estas apropriações são condicionados por inúmeras mediações, dentre as quais as mais importantes vêm das principais instituições de socialização da modernidade: a família e a escola, determinadas agora pelas características das sociedades de classes inseridas no contexto de globalização econômica e mundialização da cultura, onde as crianças e os adolescentes constituem novos segmentos de mercado consumidor mundial, 
altamente promissores, não somente por já serem consumidores importantes, mas também porque tendem a consumir por muito tempo no futuro (Belloni, 2007).

O processo de formação do ser humano - que assim se define por sua competência social (ou sociabilidade: sem sociedade não há humanidade) - tornou-se agora objeto da sociologia da infância, uma nova abordagem que busca compreender estes processos desde o ponto de vista da criança e não mais apenas desde a perspectiva das instituições (família, escola). Esta preocupação, sintetizada no conceito de sociali$z a c ̧ a ̃ o$, todavia, tem raízes antigas na sociologia, pois já a encontramos no trabalho de Émile Durkheim e Marcel Mauss, e nela se inscrevem as reflexôes aqui apresentadas (Durkheim, 1958; Sirota, 2001; Montandon, 2001; Sarmento, 2000).

No campo da educação, tem-se mesmo necessidade de conhecer melhor nossos alunos. De repente, a escola já não compreende a criança, que fala e escreve outra língua, que sabe coisas que a professora não entende muito bem e que os pais, muitas vezes, ignoram por completo, subvertendo a relação tradicional entre o adulto-que-sabe e a criança-quenão-sabe. O chamado conflito de gerações se aprofunda e toma a forma de um abismo técnico e de divergências éticas, mais radicais do que nunca, podendo gerar incompreensóes e uma incomunicabilidade maior que as descontinuidades que separavam as geraçóes precedentes.

No contexto da economia globalizada, a concentração do poder comunicacional é um fenômeno absolutamente evidente: conglomerados cada vez maiores e mais poderosos, oriundos da fusão de grandes empresas de diferentes setores da economia, buscam controlar a indústria cultural, concentrando a produção tanto de equipamentos e redes (hardware) quanto de conteúdos (software). Em face, no outro lado das telas, nos lares e em muitos espaços coletivos (salas de espera, aeroportos, ônibus, bares e, nos países ricos, até mesmo nos parques encontramos acessos à internet) temos públicos cada vez mais "cativos", ligados nas telinhas.

As crianças percebem as mensagens midiáticas a sua maneira, de acordo com as mediações que se estabelecem em seu grupo familiar, social, escolar, de pares. Vão construindo seu imaginário a partir destas significações, misturando ficção com realidade, super-heróis e personalidades políticas, catástrofes reais com violência fictícia. Em suas 
relações com as mídias, especialmente a televisão, as crianças atribuem vida e poder aos personagens das telinhas, com quem elas estabelecem relações afetivas. Uma pesquisa comparada, "TV como te quiero?", realizada com crianças de 8 a 13 anos na Argentina, no Chile e na Uruguai, revelou que elas não só atribuem vida à televisão, como também o poder de mudar o mundo (Merlo-Flores, 2003):

“TV, vos que tenes tanta influencia en el mundo convence a los adultos... para que empleen su tiempo en crear trabajo y no en hacer materiales para la guerra" (Pedro, 8 años).

“Televisión puedo soñar que un día al encenderte pueda ver un país donde todos tengamos agua y donde todos los niños puedan ir a la escuela y no tengan que trabajar..." (niña chilena, 10 años).

Também Sherry Turkle (1984), em suas pesquisas com crianças e jovens, de diferentes países, usuários mais ou menos intensivos das TIC, encontrou evidências de que as crianças conferem certos atributos psicológicos às máquinas e manifestam a preocupação de saber se e até que ponto o computador é um ser vivo. Com o uso intensivo das TIC e o desenvolvimento de uma cultura do computador pessoal, as crianças desenvolvem estratégias cognitivas e psicológicas para lidar com esta questão, tendendo a absorver reações padronizadas, consensuais, próximas às dos adultos, que estabelecem fronteiras claras entre o humano e o tecnológico. Mas esta clareza é enganadora e as fronteiras se alargaram e se obnubilaram, pelo menos para as crianças da zona altamente tecnologizada de Boston, onde se situa o Massachusetts Institute of Technology (MIT):

Para as crianças de hoje, a linha divisória que separa a pessoa da máquina mantém-se intacta. Todavia, aquilo que elas vêem através deste limite mudou dramaticamente. Agora, as crianças não se sentem incomodadas ante a idéia de que os objetos inanimados possam pensar e ter personalidade própria. No entanto, já não as preocupa saber se a máquina é ou não um ente vivo. Sabem que não é. A questão do caráter vivo ou inanimado do computador passou para segundo plano, como se estivesse resolvida. Mas a noção de máquina foi alargada, de modo a incluir o ter uma psicologia própria. (Turkle, 1997, p. 120)

As crianças nascidas na era tecnológica percebem com naturalidade estas "máquinas maravilhosas", considerando-as parceiras de suas 
vivências lúdicas e de suas aprendizagens. Apropriam-se delas a partir das mesmas estratégias que utilizam para apreender outros elementos de seus universos de socialização, sejam objetos, pessoas ou animais de estimação: agindo, apropriando-se, estabelecendo diálogos e relações. Piaget já tinha mostrado que as crianças faziam distinções semelhantes sobre o movimento das coisas para entender a diferença entre consciência e vida, conceitos que elas desenvolviam paralelamente. Segundo Turkle (op. cit., p. 121), porém, "tais simetrias chegaram ao fim”, porque hoje (nos anos de 1990) as crianças consideram como indícios de consciência e de atividades psicológicas certas características técnicas dos computadores (interatividade, capacidade de "falar", "cantar", resolver problemas de matemática).

As teorias de aprendizagem (Piaget, Vigotski...) e as abordagens institucionais (que estudam a criança do ponto de vista da escola ou da família), embora não tenham de modo algum perdido sua validade, já não dão conta de toda a complexidade do tema que nos ocupa. A rapidez do avanço técnico é tal que as gerações adultas não conseguem acompanhar e perceber com clareza a naturalidade desta apropriação espontânea, isto é, sem a intervenção didática do adulto, que as crianças e jovens costumam realizar em contato com as TIC. Uma espécie nova de autodidaxia está desafiando a escola e, por conseqüência, todo o campo da educação, a produção de conhecimento (pesquisa) como a formação de professores (Perriault, 1996; Belloni, Gomes \& Carraro, 2007; Belloni, s/d).

A importância da televisão como instituição de socialização já foi confirmada por pesquisas empíricas, não somente pelos altos índices de audiência, como também pelas representações que as crianças se fazem da televisão e de suas mensagens. A quase totalidade dos jovens percebe e é capaz de tematizar o papel socializador da telinha, sendo interessante notar diferenças entre os subgrupos de idade e de gênero, quanto às justificativas e explicações de suas preferências. As TIC, e a internet em especial, tendem a repetir com mais intensidade estes altos índices de freqüência, e seu papel nos processos de socialização, provavelmente ainda mais importante que o da televisão, ainda não foi estudado. Além de constituir uma fonte quase inesgotável de informação e de entretenimento, a internet é uma rede técnica que permite interações sociais virtuais inéditas na historia da humanidade, 
cuja disseminação, especialmente entre os jovens, vem ocorrendo com enorme velocidade, desafiando as instituições responsáveis pelos processos de socialização (famílias, escola, Estado).

Muitos estudos têm mostrado a importância crescente das mídias na criação dos "mundos sociais e culturais das crianças", onde ocorrem os processos de socialização. Nossas próprias pesquisas, realizadas em três capitais brasileiras, nas duas últimas décadas, também apontam para esta evidência: os jovens, em sua maioria e sempre que tenham acesso, são usuários assíduos, interessados e entusiastas destas novas tecnologias, especialmente a televisão e a internet. Eles têm opiniōes próprias sobre as mensagens e recursos destas mídias e, embora sejam adeptos incondicionais das telinhas, são capazes de divergir e criticar. Porém, esta capacidade crítica não é espontânea (como as aprendizagens relativas ao uso) e parece só funcionar quando o assunto interessa muito ao jovem (sexualidade ou consumo, por exemplo), ou quando a situação o estimula, no caso de uma pesquisa, por exemplo. ${ }^{1}$ Isso nos permite inferir que, embora o uso das TIC propicie aprendizagens novas, especialmente novos modos de aprender, ele não é suficiente, por si só, para desenvolver o espírito crítico e utilizações criativas. Para tal desenvolvimento serão sempre necessárias as mediações dos adultos e das instituiçôes educativas, de onde decorre a importância da formação dos professores para que estas mediaçōes se orientem a partir de uma perspectiva de mídia-educação, assegurando assim sua eficácia (Belloni, 2001a, 2001b).

A rede telemática internet, o mais novo meio de comunicação, que permite a transmissão de dados e interações simultâneas a distância, a baixos custos, veio efetivamente revolucionar as práticas culturais. No mundo todo, os mais entusiastas usuários são os jovens que se conectam às diferentes formas de interação entre pares (salas de batepapo, MSN, blogs, fotologs etc.), que tendem a ser mais freqüentadas pelas meninas, ou aos jogos eletrônicos e de papéis, onde podem viver virtualmente grandes aventuras (mais populares entre os meninos). Para a maioria das crianças e adolescentes, o computador é, antes de tudo, a máquina para conectar-se à rede. Embora os dados estatísticos mostrem crescimentos muito significativos do acesso à internet no Brasil, nos anos 2000, a acessibilidade é ainda bastante reduzida, decorrência evidente das desigualdades sociais e regionais que marcam nosso país. 
Sendo uma economia muito dinâmica, o Brasil incorpora rapidamente as inovações técnicas, porém o acesso a elas é profundamente marcado por estas desigualdades. A internet é o objeto de desejo de praticamente todos os jovens de todo o mundo. No Brasil, segundo dados do Comitê Gestor da Internet, a maioria deles, contudo, não tem acesso a ela, sendo, pois, ciberexcluídos (www.nic.br).

$\mathrm{Na}$ pesquisa com adolescentes da Grande Florianópolis (2003), por exemplo, observamos que o acesso à internet era muito maior do que supúnhamos: $73 \%$ dos jovens diziam já ter acessado a rede pelo menos "algumas vezes". É preciso considerar que nossa amostra incluía adolescentes da capital de um dos estados da região Sul que está entre os mais ricos do país e, embora tivéssemos escolas públicas de bairros periféricos em nossa amostra, não tivemos um número significativo de jovens muito carentes, que são legião nas escolas públicas. Um olhar mais atento nos revela, todavia, que os maiores usuários (os que "costumam utilizar todos os dias" e podem, por isso, desenvolver usos mais ativos e criativos) estão entre os alunos das escolas particulares. Por outro lado, a parte qualitativa da pesquisa, que trabalhou com crianças e adolescentes em situação de risco, ou seja, muito carentes, revelou-nos que o acesso às TIC ainda está longe de uma distribuição democrática e que operar um computador (mesmo sem acesso à internet) é ainda um objeto de forte desejo (Belloni, 2008; Belloni, s/d).

Para compreender as relaçôes entre as TIC - entendidas como processos comunicacionais - e os processos educacionais (a que chamamos genericamente "educação"), é imprescindível aprender com os aprendentes, sujeitos dos processos de socialização, isto é, as crianças e adolescentes, simplesmente porque, para eles, nascidos nesta era da informática e das telecomunicações, as TIC são tão naturais quanto qualquer outro elemento de seu universo de socialização. Estão, portanto, mais aptos (que nós, adultos) a extrair delas o melhor e o pior para construir sua formação.

Por sua presença incontornável na vida cotidiana da grande maioria das crianças do planeta, a televisão é a mídia de maior alcance e importância nos processos de socialização das novas gerações. A internet, com certeza, está se acrescentando a este processo, tendendo a substituir alguns, mas não todos, usos da televisão. $\mathrm{O}$ poder de influência destas mídias é enorme, dificilmente mensurável em toda sua 
complexidade. Profundas desigualdades se estabelecem, de um lado, entre as crianças consumidoras/receptoras de mensagens e os grandes conglomerados produtores de conteúdos; e, de outro lado, entre as próprias crianças segundo suas distinções de classe (e, portanto, de acesso e até de capacidade crítica). Evidentemente, estas desigualdades, que tendem a agravar-se com o avanço e disseminação destas tecnologias, são também condicionadas pela variável econômica, caracterizada pela globalização.

Parece inegável no Brasil a permanência de desigualdades estruturais sociais (de acesso a bens materiais, culturais e técnicos), mas também culturais e políticas: sentimento e percepção da cidadania fragilizados pela situação de pobreza e exclusão, dificultando o desenvolvimento de processos de autonomia e emancipação; níveis baixíssimos de informação e consciência política, especialmente entre os jovens, de todas as classes sociais; baixa auto-estima e bloqueios psicológicos, indisponibilizando muitas crianças e adolescentes carentes para as aprendizagens indispensáveis à vida social. Por outro lado, conglomerados de comunicação poderosíssimos se consolidam e constroem uma espécie de universo paralelo, criando, através de suas mídias, eventos importantes que interferem tanto no cotidiano do cidadão, quanto na esfera política institucionalizada. Estas desigualdades se manifestam na situação da infância e da adolescência, a partir da qual se pode perceber com muita clareza duas características marcantes da sociedade brasileira: a desigualdade e a exclusão. Consideramos este fenômeno determinante para a compreensão da situação social da infância brasileira: a exclusão de uma grande parte das crianças e adolescentes dos benefícios sociais mais fundamentais, inclusive aqueles legalmente garantidos na Constituição e no Estatuto da Criança e do Adolescente (ECA): proteção, provisãa, acesso à educação e à comunicação de qualidade (o que, teoricamente, asseguraria o terceiro "p", de participação). Tal situação gera mecanismos de desigualdade que se acumulam, se auto-reproduzem e se reforçam, à medida que os sujeitos infantis e juvenis avançam em seus processos de socialização.

Assim, quando a criança muito pobre chega à escola, aos 6 ou 7 anos, ela já traz consigo as marcas de sua condição social de desigualdade e exclusão do universo letrado ao qual pertence a escola. Contudo, estas marcas ainda não são indeléveis e a escola teria possibilidades 
de integrar esta criança à cultura letrada e ao universo da informação escrita e eletrônica e do saber acumulado pela humanidade. À medida que a criança vai avançando em sua trajetória escolar, ela vai, em muitos casos, perdendo as possibilidades de integração, e as marcas de sua exclusão "por dentro" da escola vão ficando mais profundas, as desigualdades vão se agravando. Quando chegam à adolescência, muitas destas crianças, escolarizadas há anos, mas não alfabetizadas plenamente, totalmente excluídas do letramento, estão de tal modo traumatizadas por um processo escolar de fracasso e pela exclusão social, que têm poucas possibilidades de assimilar qualquer coisa que lembre a escola e seu fracasso. Estes jovens chegam ao limiar da vida adulta sem as condiçôes socioculturais mínimas para a vida em sociedade, sem a devida preparação profissional, por exemplo, mas não somente. Estão também despreparados para a cidadania, para conhecerem e exercerem seus direitos e deveres e agirem como cidadãos responsáveis. São os "excluídos por dentro" (Bourdieu, 1993), muitas vezes ignorados pelos professores, que não sabem como lidar com estes alunos. Sua presença é às vezes percebida pelos professores como signo do fracasso da escola e, pelos colegas, como diferente, incongruente, pois destas crianças não se exige o mesmo que para todas as outras. Confirmam estas percepções depoimentos de professores de uma de nossas pesquisas, realizada em uma escola pública de Florianópolis, com alunos em situação de vulnerabilidade social, no ano de 2005, por exemplo:

Os alunos percebem que não sabem e isso bloqueia novas aprendizagens. Têm baixa auto-estima, se sentem inferiorizados. Se auto-rotulam como incapazes de fazer... Outros não estão "nem aî", não se "ligam" que precisam aprender alguma coisa; a participação em sala de aula é quase nula; a escola pouco pode fazer, precisariam de ajuda especializada.

Novos modos de aprender com as TIC

A escola poderia e deveria funcionar no sentido de compensar tais desigualdades, oferecendo a crianças e jovens desfavorecidos os meios de ingressar no mundo do letramento e da "cultura digital". Deveria também aperfeiçoar métodos, técnicas e conteúdos para estar mais em sintonia com "os mundos sociais e culturais da infância", criados por crianças e adolescentes, especialmente os das classes sociais 
favorecidas, já perfeitamente incluídos na "cultura digital" e capazes de perceber, às vezes com uma clareza surpreendente, o fosso tecnológico que separa a escola da vida social.

Para isso, é necessário não apenas investir em equipamentos e formação de professores, mas antes de tudo re-inventar a pedagogia com base em estudos e pesquisas que ajudem a compreender como as crianças aprendem hoje. Com esta perspectiva, na última fase de nossas pesquisas (2004/2006), procuramos estudar como as crianças se apropriam de ferramentas informáticas e quais as habilidades e competências cognitivas e motoras estão sendo propiciadas e mobilizadas no uso pedagógico dos computadores, especialmente duas variáveis definidas como: a autodidaxia e a aprendizagem colaborativa e cooperativa. ${ }^{2} \mathrm{Os}$ parágrafos a seguir sintetizam algumas das principais inferências decorrentes deste estudo.

O trabalho de reflexão teórica e de pesquisa empírica que fundamenta este texto parte de uma hipótese que é quase um pressuposto: as TIC atingem contingentes cada vez mais numerosos de jovens, inclusive aqueles menos favorecidos, habitantes das periferias urbanas, o que torna ainda mais importante e urgente sua integração ao quadro escolar, numa perspectiva de mídia-educação, em sua dupla dimensão de ferramentas pedagógicas e objetos de estudos (Belloni, 2001a, 2002). Esta segunda dimensão é fundamental, sobretudo se considerarmos que os conteúdos mais recorrentes nas mídias voltadas ao público jovem apresentam imagens que conotam ao mesmo tempo violência, ação e sensualidade e relacionam estes temas com a música, o desenho, a dança, a expressão corporal, uma espécie de "mixagem" que caracteriza as mensagens globalizadas e que é expressão de uma nova "cultura jovem digital mundializada" (Belloni, 1994, 2004).

As outras hipóteses que orientam nosso trabalho de pesquisa empírica podem ser assim resumidas:

- No uso das TIC, crianças e jovens desenvolvem modos novos de aprender e novas habilidades cognitivas desconhecidos ou ignorados dos professores (autodidaxia).

- As TIC favorecem a aprendizagem cooperativa e/ou colaborativa porque ampliam as possibilidades de interação entre alunonalunonprofessor, numa rede de relaçóes que engendra 
conflitos sócio-cognitivos e facilita a percepção por parte dos alunos de seus próprios processos cognitivos.

- As crianças e jovens usam com habilidade e familiaridade estas técnicas, desde que tenham acesso a elas, ou seja, seu uso tende a generalizar-se. Esta generalização é acelerada pela atração exercida por estas técnicas nas gerações que, desde pequenas, vivem entre mídias eletrônicas, especialmente a televisão.

- As crianças e jovens desfavorecidos, que não têm acesso às TIC, podem desenvolver aquelas habilidades e modos de aprender, uma vez que tenham acesso a ambientes ricos em tecnologias e a situaçōes favoráveis de aprendizagem que tendem a estimular os processos psicológicos superiores, transformando-os em outros processos cognitivos.

O objetivo de nossas pesquisas é compreender como as crianças aprendem no contato com as TIC, considerando que estas tecnologias fazem parte do meio ambiente sociocultural no qual elas evoluem, e de cujos elementos elas se apropriam enquanto atores de seu desenvolvimento intelectual e sócio-afetivo. A análise de estudos e pesquisas (inclusive as nossas) nos leva a acreditar que a interação entre pares e com adultos, em situaçóes favoráveis e inovadoras de aprendizagem e com uso pedagógico apropriado das TIC, pode levar as crianças em geral e, em especial, aquelas menos favorecidas, a desenvolver comportamentos colaborativos e autônomos de aprendizagem, altamente eficazes e benéficos para seu desenvolvimento intelectual.

Os psicólogos sociais de Genebra (Willem Doise, Gabriel Mugny e Anne-Nelly Perret-Clermont, entre outros) retrabalharam muitas das idéias de Piaget sobre o desenvolvimento intelectual das crianças, à luz das teorias da reprodução (Bourdieu e Passeron) e da sociolingüística (Bernstein e Labov). As concepções iniciais de Piaget sobre a interação cooperativa como fator de desenvolvimento cognitivo fornecem um quadro teórico geral para estes estudos, que pretendiam verificar se a intensificação das interações entre pares e entre crianças e adultos poderia, em certas condições, compensar as deficiências de crianças de origem social desfavorecida frente à instituição escolar. Tratava-se de estudar "a anterioridade de uma forma de interação social que se refletirá na aquisição de novas competências individuais em operações cognitivas 
(no sentido de Piaget)". Não podemos apresentar aqui toda a imensa riqueza destas pesquisas, mas é importante referir alguns conceitos fundamentais para a compreensão de nossas variáveis de estudo (aprendizagem colaborativa e autodidaxia): coordenação das açôes, atualização de instrumentos cognitivos, operaçōes cognitivas transponiveis, conflitos sóciocognitivos, regulaçôes sociais (normas, representaçôes). Embora estas pesquisas não tenham enfocado o uso de TIC, elas contribuem para a compreensão de seu papel nestes processos, no sentido de melhor perceber as desigualdades de origem social, pois mostraram, entre outras coisas, que uma interação entre pares, breve mas apropriada, fazendo intervir o conflito sócio-cognitivo e/ou normas ou representações diferentes ("marcação social"), permitia a crianças de meios sociais desfavorecidos atingirem os níveis que as crianças mais favorecidas atingem sozinhas (Doise, 2007, p. 126-128).

Nossas pesquisas permitiram observar, em muitas ocasiōes, o quanto a interação entre pares desempenha um papel crucial nas aprendizagens e o quanto o uso pedagógico adequado das TIC favorece estas interaçôes, na medida em que cria ambientes de aprendizagem mais dinâmicos e mais democráticos do que a sala de aula convencional, favorecendo a aprendizagem colaborativa. O mesmo podemos dizer sobre a autonomia do aprendente, esta qualidade indispensável ao desenvolvimento da autodidaxia, uma competência ao mesmo tempo propiciada por elas e necessária, até mesmo imprescindível, na apropriação das técnicas de informação e comunicação que povoam nossa existência. Esta competência, relacionada com a capacidade de "aprender a aprender" de que falam os discursos educacionais em voga, é fundamental para a vida social contemporânea, seja para o trabalho, seja para a cidadania.

As observações realizadas com crianças e adolescentes de diferentes origens sociais nos permitiram constatar que crianças e jovens que têm acesso às TIC fora do ambiente escolar desenvolvem competências para o uso desses artefatos, tanto na interatividade com a máquina quanto na interação com seus pares. Foi possível observar que eles constroem relaçōes, trocam conhecimentos e "dicas" sobre a melhor maneira de atuar, se empenham em um trabalho de administração real, aprendem a avaliar riscos, observam os resultados de suas decisōes e se permitem falhar muitas vezes antes de atingir seus objetivos. Isso diz 
respeito às crianças com acesso domiciliar e experiência na apropriação destas tecnologias. Porém, acreditamos que possa ser generalizado a crianças menos favorecidas, desde que o acesso aos equipamentos e a criação de situaçóes de aprendizagem adequadas lhes sejam oferecidos. Muitos relatos de pesquisa nos mostram que crianças que vivem em processo de exclusão social também podem desenvolver essas mesmas competências, quando têm oportunidade de acesso (Merlo-Flores, 2003; Castro, Moura \& Ribeiro, 1999; entre outros).

Nossa hipótese é de que ambientes de aprendizagem computacionais são potencialmente muito eficazes para trabalhar com essa clientela desfavorecida, porque possibilitam a mediação entre o sujeito e o objeto do conhecimento a ser construído, conforme sugerem os aportes das teorias construtivista e sócio-interacionista. Piaget nos diz, por exemplo, que o interacionismo caracteriza-se pelas trocas entre o sujeito e o meio que ocorrem tanto do ponto de vista intra-individual como do inter-individual:

Para o desenvolvimento cognitivo, explica Piaget, são determinantes os fatores sociais de cooperação ou coordenação interindividual das ações (...). Não se trata das relações sociais de coação subordinadas ao fator de obediência ou de autoridade, mas das relações de cooperação, que são caracterizadas pela reciprocidade e por regras autônomas de conduta fundamentadas no respeito mútuo. (Fagundes, 1999, p. 31)

Vigotski, por sua vez, enfatiza que a construção do conhecimento ocorre em ambientes influenciados pela ação do sujeito sobre o meio e pelas mediaçóes entre ele e seus pares, que favorecem o desenvolvimento de processos mentais superiores quando empregados num ciclo que pressupõe descrição-execução-reflexão-depuração de idéias na resolução de problemas (Valente, 1993). Para Vigotski (1987, p. 17), “(...) a colaboração entre pares durante a aprendizagem pode ajudar a desenvolver estratégias e habilidades gerais de solução de problemas através da internalização do processo cognitivo implícito na interação e na comunicação".

$\mathrm{Na}$ interação de crianças e adolescentes com videogames e computadores, utilizando games, softwares ou navegando na internet, percebe-se que, movidos pela motivação e pela curiosidade, eles atingem 
o domínio do que estão fazendo e são capazes de avançar para níveis cognitivos superiores, além de adquirirem o conhecimento necessário para manipular o próprio equipamento (comandos, funções, configurações etc.), ou seja, desenvolvem a capacidade de aprender sozinhos (Greenfield, 1988); Turkle, 1984, 1997; Merlo-Flores, 2003). Perriault (1989) explica que esta autodidaxia é uma característica essencial dos modos de aprendizagem das crianças e jovens em sua relação com as máquinas de informação e comunicação.

Nossa pesquisa busca compreender como ocorrem estes "novos modos de aprender" (Babin \& Kouloumdjian, 1989), que já vêm se desenvolvendo - à revelia da escola e, de modo geral, ignorados por professores e especialistas - desde que as crianças começaram a aceder à televisão e aos videogames e se amplificaram e complexificaram com o acesso e uso lúdico do computador e da internet.

A construção do conhecimento é um processo interativo de estruturação recíproca entre sujeitos e meio-ambiente, interno e externo, dinâmico, que se desenvolve no tempo. Piaget mostrou que a ação prática espontânea (para a qual a natureza nos dotou de uma série de mecanismos automáticos, nos quais nem temos necessidade de pensar) é apenas a primeira etapa do acesso ao conhecimento. Piaget foi duramente criticado, mas ele permanece o autor que, como Vigostski, deu uma contribuição fundamental para a compreensão desta problemática: o conhecimento humano começa por se enraizar na ação prática em relação ao meio-ambiente, mas evolui para a abstração (de tipo científico) e só se formaliza se superar este estágio. Um ambiente de aprendizagem rico em tecnologias pode contribuir para este processo, baseado na ação do aprendente, que vai de uma ação prática a uma operação cognitiva de abstração:

As TIC são, por excelência, ferramentas interativas para ver, fazer, representar e trocar. Elas são, pois, particularmente apropriadas ao acompanhamento da ação empírica e aos métodos das pedagogias ditas "ativas", no sentido de C. Freinet, ou "interativas" no sentido sócio-cognitivo atual. Bem utilizadas em todo seu potencial cognitivo de manipulação, transformação, circulação e estocagem de conhecimentos, elas (as TIC) podem também prestar grandes serviços aos aprendentes experientes em sua passagem à conceitualização. (Linard, 2000, p. 7) 
Autonomia, colaboração e autodidaxia

Os autores mencionados anteriormente destacam a importância do trabalho cooperativo e/ou colaborativo entre pares para aprender mais e melhor. E necessário definir precisamente o significado dos termos cooperação e colaboração, tal como o utilizamos em nosso trabalho. Na literatura recente sobre o tema, alguns autores consideram que os conceitos são sinônimos; para outros, contudo, existe uma diferenciação, especialmente, no que diz respeito ao envolvimento de cada participante do grupo para a resolução da tarefa. Para Tijiboy et al. (1999, p. 19-28), por exemplo:

O conceito de cooperação é mais complexo que o de interação e de colaboração, pois, além de pressupor ambos, requer relações de respeito mútuo e não hierárquicas entre os envolvidos, uma postura de tolerância e convivência com as diferenças e um processo de negociação constante. (...) a diferença fundamental entre os conceitos de colaboração e cooperação reside no fato de que para haver colaboração o indivíduo deve interagir com o outro, existindo ajuda - mútua ou unilateral. Para existir cooperação deve haver interação, colaboração, mas também objetivos comuns, atividades e ações conjuntas e coordenadas.

Castaneda y Figueroa (apud Santarosa, 1999, p. 6) vão adiante, definindo o trabalho cooperativo em relação à aprendizagem e ao sucesso no alcance de objetivos:

A atividade de aprendizagem pode ser oportunizada de forma cooperativa se os alunos estiverem estritamente ligados, de maneira que cada um deles saiba e sinta que seu êxito pessoal ajuda os colegas aos quais está unido a alcançar o deles; os resultados almejados por cada membro do grupo são, portanto, benéficos para os outros membros com os quais está interagindo cooperativamente.

A cooperação vai, pois, além da colaboração: existe colaboração mesmo quando não há compromisso com a realização de um projeto; passa a haver cooperação quando existe um trabalho em comum relacionado com o sucesso de um projeto comum. Muitos autores têm afirmado que o uso criativo das TIC e a construção de ambientes de aprendizagens computacionais potencializariam a interação entre aluno $\leftrightarrow$ 
aluno $\leftrightarrow$ professor, numa rede de relaçôes cooperativas e colaborativas altamente propicias à aprendizagem, além de promover a ocorrência de conflitos sócio-cognitivos e facilitar a percepção por parte dos alunos de seus próprios processos cognitivos, utilizados na realização da tarefa proposta (Papert, 1994; Valente, 1999; Santarosa, 1999; Fagundes, 1999; Almeida \& Fonseca, 2000; Perriault, 2002).

Projetos coletivos de trabalho ou de aprendizagem, realizados em ambientes computacionais, são meios adequados para desenvolver atividades cooperativas ou colaborativas mediadas pelas tecnologias, pois possibilitam a vivência de situaçōes diferentes das que os alunos costumam experimentar numa situação de ensino convencional. Em projetos coletivos de aprendizagem, os objetivos pedagógicos e cognitivos que se quer alcançar são: a contextualização do tema, a tomada de decisōes em grupo, as situaçōes de troca, a reflexão individual e coletiva, a tolerância e a convivência com as diferenças, as constantes negociações e as ações conjuntas (Hernández, 1998; Almeida, 1999; Fagundes et al., 1999). As experiências de uso pedagógico das TIC observadas em nossas pesquisas foram organizadas segundo estas características: aprendizagem por projetos e ambientes de aprendizagem construídos a partir das teorias construtivistas (Belloni, Gomes \& Carraro, 2007).

Tais características devem favorecer tanto a aprendizagem colaborativa e cooperativa, quanto a aprendizagem autônoma e a autodidaxia. Segundo Perriault (2002), a aprendizagem cooperativa ocorre quando a aquisição de competências e de conhecimentos é resultado da integração (ou interiorização) de um ponto de vista de outrem, em um grupo de pares com uma meta partilhada e negociada, no qual cada participante pode desenvolver competências individuais que não tinha no início. É preciso, pois, distinguir cooperação e colaboração. A cooperação é uma relação que permite a cada um frutificar o que ele traz, enquanto a colaboração demanda a reciprocidade, o que implica ser capaz de confiar nos outros para apoiar sua própria aprendizagem num ambiente não competitivo. A cooperação ocorre, pois, na realização de um projeto de aprendizagem, enquanto a colaboração pode ocorrer em outras atividades como, por exemplo, os jogos. As relaçôes que se estabelecem em rede podem desempenhar um papel importante na aprendizagem, como o grupo de pares ou as comunidades de práticas. 
Ainda segundo Perriault (um dos pioneiros na pesquisa com adolescentes sobre jogos eletrônicos), para utilizar as TIC, especialmente as redes telemáticas, seja para fins pedagógicos, seja para finalidades puramente lúdicas, é imprescindível "aprender a aprender", único modo de não ficar excluído, pois não há métodos de ensino destas práticas que são, em sua maioria, espontâneas. Além disso, as práticas espontâneas tenderiam a diminuir a distância entre o autor e o usuário dos conteúdos e jogos. A metacognição intervém na faculdade de aprender a aprender: a reflexão e a verbalização das condutas e processos cognitivos permitem que o sujeito aprendente avance em seu processo, internalizando as etapas vencidas e projetando as etapas ainda por desenvolver. $\mathrm{O}$ autor destaca a imensa vantagem dos mais jovens na compreensão destes jogos e na construção de conhecimentos via autodidaxia, pela transposição massiva dos efeitos da televisão em uma geração que foi alimentada por ela e que "pergunta como torná-la mais interativa" (2002, p. 112). Esta é uma temática que ainda exige muita pesquisa para compreendermos efetivamente como ocorrem estas aprendizagens nas crianças e adolescentes, mas já podemos inferir efeitos importantes do uso destes jogos e dos diferentes recursos da internet nas habilidades e competências relacionadas com as mais diversas aprendizagens (MSN, blogs, softwares de "autoria", comunidades do tipo Orkut ou Facebook etc.). Não sabemos, porém, quase nada sobre como estas aprendizagens se realizam:

Não sabemos, salvo as exceções examinadas aqui, se o sujeito constrói conhecimentos [ao jogar] e quais. Podemos nos perguntar, aliás, se ele não o faria melhor construindo jogos, como é o caso do grupo de jovens com quem trabalhamos, o que remete à hipótese de Papert em 1980 [com a criação do software LOGO]. Nem todo mundo pode construir jogos, mas existem, talvez, soluções intermediárias a explorar. (...) Em todo caso, o futuro deveria conhecer múltiplas interaçôes entre a perspectiva construcionista e a evolução dos jogos informatizados. (Perriault, 1996, p. 112; meu grifo)

Hoje, já podemos dizer que as "soluções intermediárias" existem nas múltiplas formas de "programas de autoria" e se difundem com rapidez, sendo apropriadas por crianças e jovens na produção de seus blogs, sites, perfis, fotologs, seleção e cópia de músicas para o ipod etc. 
Também não sabemos, por exemplo, quase nada sobre esta capacidade de "processar em paralelo", ou seja, realizar mais de uma atividade mental ao mesmo tempo, que as novas geraçóes vêm desenvolvendo no uso das TIC, sendo a mais conhecida a capacidade de fazer os deveres escolares ao mesmo tempo em que assistem a seus programas preferidos de televisão. Os dispositivos técnicos obrigam constantemente o usuário a efetuar várias tarefas de uma vez. A informática exige todo o tempo que o utilizador gerencie vários processos em paralelo, isto é, organize interrupções e retomadas de tarefas: eventos inesperados desencadeiam o congelamento de um processo em curso e solicitam a

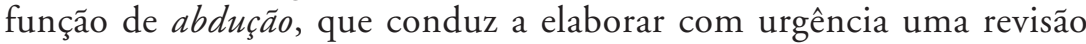
eventual do procedimento, bem como da hipótese de ação (Perriault, 1996).

Dito desta forma, parece muito complexo, mas esta é uma descrição, no jargão das ciências cognitivas, dos procedimentos cognitivos que efetuamos comumente quando estamos usando um computador conectado à internet: escrevemos um texto no Word, consultamos bancos de dados cujas informaçôes podemos incorporar em nosso texto, recebemos mensagens em nosso e-mail, podemos escutar música, jogar, participar de um fórum de discussão, ler e/ou acrescentar um comentário ou uma foto em nosso blog, sem esquecer de estarmos ligados ao MSN e "entrar" nele sempre que houver interesse etc. Todas estas atividades são simultâneas e se encadeiam, uma interrompendo a outra, sempre que ocorre "um evento novo" (por exemplo, o amigo que entra no MSN). Estes são os modos de uso das TIC que nossas crianças e adolescentes fazem todos os dias, em alguns casos, durante muitas horas. Em comparação com estas atividades, que mobilizam competências cognitivas complexas, mesmo se o conteúdo das "tarefas" pode nos parecer sem interesse, a sala de aula convencional deve parecer às crianças linear, sem graça e totalmente desinteressante, senão pelos conteúdos (que podem interessar às crianças), certamente pela forma (magistral, hierárquica, expositiva, com quadro de giz e pouquíssimas imagens).

A observação de situações cotidianas mostra, contudo, que nem todos têm a mesma facilidade para efetuar tais gestôes em paralelo. Podemos admitir a hipótese de que o uso precoce e lúdico das TIC contribui fortemente para o desenvolvimento desta importante habilidade 
cognitiva, indispensável para a vida nas sociedades contemporâneas altamente tecnificadas. Considerando que este uso é privilégio daquelas crianças mais favorecidas, que têm acesso domiciliar às TIC, é forçoso concluir que este acesso desigual pode gerar profundas desigualdades, inclusive no próprio desenvolvimento cognitivo. Nossa pesquisa, evidentemente, não tem a pretensão de verificar tal hipótese inquietadora. Para isso, serão necessários muitos anos de pesquisa interdisciplinar e de grande porte. Pretendemos apenas contribuir modestamente para mostrar o quanto estas TIC são importantes para a aquisição de certas aprendizagens básicas, especialmente a alfabetização, e o papel fundamental que a escola pública pode desempenhar para compensar as terríveis desigualdades sociais que caracterizam a sociedade brasileira. Nossas variáveis de análise são a aprendizagem cooperativa e colaborativa e a autodidaxia, aspectos propriamente cognitivos de uma competência mais ampla, que significa essencialmente pensar por si mesmo: a autonomia.

Segundo Montandon (2007, p. 105-126), a autonomia é uma qualidade imprescindível para o indivíduo moderno e, por conseqüência, "uma meta a buscar na educação das crianças, uma competência". As conseqüências pedagógicas desta perspectiva são fundamentais: é preciso levar em consideração as idéias, as emoções, as atitudes do educando, especialmente a criança, que deve estar no centro do processo pedagógico. Não se pode obrigar a criança a executar a vontade do adulto, mas deve-se buscar seu consentimento, sua autonomia, sua responsabilidade, sua inteligência. As crianças são tratadas como seres dotados de razão, capazes de tomar por si próprios decisões corretas (Montandon \& Longchamp, 2003). Pesquisas no campo da psicologia mostraram que "a autonomia se inscreve nas interaçóes das crianças desde a idade pré-escolar. Ela emerge e se desenvolve nos bem pequenos e aparece em suas justificações durante episódios de conflitos e em suas avaliações das intervençôes dos professores" (idem, ibid., p. 17).

Evidentemente, esta competência nascente em crianças muito pequenas vai necessitar de condições favoráveis em seu universo de socialização (sociocultural, familiar, escolar etc.) para se desenvolver ou se atrofiar. Podemos inferir facilmente que, vivendo em um ambiente desfavorável, submetida a um poder autoritário (na família, na escola) ou a uma crença religiosa fundamentalista, por exemplo, ou, 
ainda, exposta a situações de risco e violência, a criança dificilmente desenvolverá satisfatoriamente sua autonomia. Para nossos objetivos importa enfatizar que esta competência fundamental, definida como $a u$ tonomia, existe em potencial em todas as crianças e pode ser favorecida ou não por ambientes de aprendizagem mais ou menos favoráveis. Acreditamos que ambientes de aprendizagem ricos em TIC podem contribuir significativamente para o desenvolvimento da autonomia, tanto em termos sócio-afetivos quanto propriamente cognitivos. Tais ambientes podem ser informais, em casa, quando as crianças fazem um uso lúdico sem intervenção do adulto, ou percebem que são mais competentes que este; ou formais, na escola, sobretudo se associados a projetos coletivos de aprendizagem de interesse das crianças.

Aprendizagens mais felizes com as TIC

Ao final de uma pesquisa com crianças de educação infantil, realizamos algumas entrevistas para captar suas avaliaçôes sobre nosso projeto de uso pedagógico de materiais videográficos ("O vídeo na préescola”, 1996). Dentre as muitas opiniōes positivas, expressas com uma clareza surpreendente em crianças tão pequenas, a que mais nos marcou foi a de uma menina, que resume perfeitamente o sentimento das crianças com relação à presença das mídias na sala de aula: "Com a televisão, a aula ficou mais feliz!”.

Pudemos observar, nesta pesquisa já antiga, que o uso da televisão como ferramenta pedagógica agrada às crianças, estimula o interessa, provoca satisfação. O vídeo, como suporte pedagógico, estimula as crianças a mobilizarem seus referenciais televisuais, suas competências específicas de leitura televisual, gerando grande motivação, inclusive para outras aprendizagens como a da leitura. Observamos também que este uso estimula as crianças a trocarem informações e opiniōes sobre programas, heróis e histórias, mas também sobre questões técnicas, criando situações de aprendizagens colaborativas e gerando a construção de conhecimentos e atitudes de leitura crítica dos conteúdos da telinha.

Quase dez anos depois, ao longo da observação de outras experiências de uso do computador como ferramenta pedagógica, foi possível observar as mesmas atitudes positivas, satisfação, interesse e vontade de aprender e participar. Observamos, de modo recorrente, comportamentos de aprendizagem autônoma e colaborativa e, também, com relativa 
frequiência, uma combinação de autodidaxia e colaboração. Além disso, de modo geral, as crianças se mostram capazes de manejar diferentes variáveis ao mesmo tempo, por exemplo, na solução dos jogos, no uso dos software de autoria, ou quando prestam atenção ao trabalho da dupla de colegas no computador ao lado. Estas habilidades cognitivas, que revelam a capacidade de "processar em paralelo" desenvolvida, provavelmente, na interatividade com os videogames, televisão e computador, são, evidentemente, bem mais freqüentes nas crianças favorecidas que têm acesso domiciliar às TIC.

O desenvolvimento de comportamentos de colaboração é também fortemente favorecido pelo uso precoce e lúdico destas TIC. Pudemos observar o quanto as crianças demonstram satisfação em compartilhar suas descobertas, como parece natural ajudar os colegas menos experientes e o quanto a troca e a partilha entre pares são importantes para as descobertas e a consolidação das aprendizagens.

Uma de nossas descobertas mais interessantes e importantes, do ponto de vista pedagógico, foi a relação entre o uso do programa de processamento de texto e a alfabetização. Observamos que todas as crianças gostam de "escrever no computador", mesmo as que ainda não estão alfabetizadas, e que elas são capazes de identificar e valorizar as vantagens da escrita neste equipamento, com relação ao papel. A recorrência destas observações confirma nossa convicção de que o computador pode ser uma ferramenta preciosa no processo de alfabetização de crianças desta faixa etária, em qualquer classe social. Isso porque escrever no computador é percebido como uma atividade lúdica, gerando maior motivação e interesse, facilita o desenvolvimento do processo motor da escrita e os processos cognitivos de aquisição da leitura. As crianças são capazes de perceber as diferenças entre as atividades na sala de aula e na sala informatizada: para elas, "escrever no computador é mais fácil e mais prático". "No computador, escrever é automático!", declara enfaticamente uma menina da $2^{\text {a }}$ série do ensino fundamental. A maioria percebe as vantagens do programa de tratamento de texto: "não borra"; "apaga mesmo e fica tudo bem limpinho", fazendo desaparecer o erro, ao contrário da borracha no papel, que "mancha e suja a folha", de certa forma agravando e perpetuando as marcas dos erros.

Podemos dizer, com base em nossas observaçôes, que o uso das TIC, em situações pedagógicas favoráveis e com projetos pedagógicos 
estruturados, contribui para desenvolver comportamentos de autonomia e autodidaxia e favorece o trabalho colaborativo, além de ser uma ferramenta especialmente valiosa para a aquisição e consolidação da alfabetização. As razões apontadas acima, relacionadas à facilitação do processo de alfabetização pelo uso pedagógico de TIC, podem ser estendidas ao conjunto de aprendizagens que a escola tem por função promover. Vimos, por exemplo, a construçãa, autônoma e espontânea, por alunos de $2^{\text {a }}$ série, ao ilustrarem suas histórias utilizando o programa MicroMundos (Papert, 1994), da noção de perspectiva, conceito importante de representação gráfica de relações espaciais que a humanidade levou séculos para construir e que as crianças de hoje assimilam "naturalmente" pelas telinhas a que têm acesso. Cabe ressaltar, mais uma vez, que encontramos também evidências de que o uso pedagógico das TIC pode potencializar a motivação e a disponibilidade psicológica para aprender, sem as quais não há aprendizagem. Este potencial é extremamente importante para crianças e adolescentes desfavorecidos, para os quais o acesso às TIC na escola é fonte de sentimentos de auto-estima, condição necessária, embora não suficiente, para a aprendizagem.

Observamos claramente nestas experiências que as crianças percebem como muito positivas a interatividade com o computador e o valorizam tanto como ferramenta para o trabalho escolar, quanto como máquina de brincar, que propicia aprendizagens importantes. Do ponto de vista propriamente cognitivo, foi possível observar a ocorrência freqüente daqueles aspectos fundamentais apontados pelos psicólogos de Genebra, referidos anteriormente, permitindo perceber claramente que a interação entre pares, em situaçôes de aprendizagem colaborativa, estimulada e enriquecida pelo uso das TIC, cria condiçôes muito favoráveis ao desenvolvimento cognitivo. Vimos, por exemplo, as regulaçóes de ordem social (normas e representações) pelas quais são regidas as interações entre os pares e entre adultos e crianças, numa situação escolar de aprendizagem: "constituem fatos importantes no estabelecimento de novas coordenaçôes cognitivas" (Doise, 2007, p. 126). Também observamos que, apesar de níveis relativamente altos de autonomia reflexiva e relacional, surpreendentes em crianças tão pequenas, a intervenção dos adultos de referência é extremamente importante para o desenvolvimento das crianças, tanto em termos cognitivos quanto sócio-afetivos. Embora este último aspecto tenha sido mais claramente observável em adolescentes muito carentes, a experiência de alunos de 
uma escola particular, participantes de um projeto de aprendizagem muito complexo de construção de jogos computacionais de matemática, também mostrou a importância da intervenção orientadora do adulto (Belloni \& Gomes, 2004).

\section{Desigualdades sociais e exclusão por dentro da escola}

A análise das experiências com crianças e adolescentes muito desfavorecidos, vulneráveis, em situação de risco, com vivências extremamente difíceis e marcantes, revela-nos, em primeiro lugar, uma realidade de terrível desigualdade social: embora vivendo na capital de um dos estados mais ricos do país e freqüentando a escola pública regular, estas crianças estão totalmente excluídas do acesso mínimo a qualquer bem cultural, muito especialmente àquilo que se convencionou chamar de "cultura digital". Tal situação de exclusão dificulta ou mesmo impede que estas crianças e adolescentes vivenciem processos de desenvolvimento intelectual e psicossocial satisfatórios, acumulando atrasos cognitivos e sócio-afetivos que vão se transformar, na adolescência, em obstáculos quase intransponíveis para qualquer aprendizagem. Como sabemos, o desenvolvimento intelectual é produto das interações entre o sujeito e seu meio ambiente sociocultural e natural. Considerando as características particularmente difíceis, hostis, precárias e confusas, tanto em termos sócio-normativos, quanto em termos culturais e cognitivos, do universo de socialização de nossos sujeitos, podemos inferir, baseados em Piaget, Vigotski e outros autores construtivistas, que estas características se refletem nos modos de pensar e de aprender destas crianças. Elas têm dificuldades de concentração, raciocinam de modo que nos parece ilógico - talvez pudéssemos dizer no modo de "bricolagem", no sentido de Lévi-Strauss -, parecem inaptas à abstração e se mostram, praticamente o tempo todo, desmotivadas e desinteressadas com relação às tarefas que identificam como escolares. Tais características aparecem de modo recorrente em crianças e adolescentes vulneráveis, vivendo em situação de risco, e parecem torná-los, senão impermeáveis, pelo menos inadaptados às formas de pensar e de aprender que a escola impóe e desenvolve, gerando frustrações e bloqueios (Belloni, Gomes \& Carraro, 2006).

É importante ressaltar que tais fatos são sociais e não naturais e, portanto, não são imutáveis nem necessariamente determinantes. É 
missão do cientista social, que os analisa e que compreende as ciências sociais como uma possível contribuição para a mudança, colocar em evidência os fatores sociais que determinam tais situações de "exclusão-pordentro-da-escola" e contribuir para pensar possíveis cenários de mudança. A pobreza de nossos morros se reflete na pobreza da escola, que sofre com a penúria característica do ensino público no Brasil, onde os esforços dos professores se perdem diante do cotidiano deletério que vivem estes jovens e das condições de trabalho muitas vezes penosas e frustrantes. Vivendo num contexto social de extrema pobreza, violência e exclusão social e cultural, mas incluídos pelas mídias (especialmente a TV) no espetáculo que celebra as maravilhas do consumo e do progresso técnico, estes jovens encontram dificuldades em construir sua identidade. Frequentando uma escola que os exclui simbolicamente, pois não consegue integrá-los ao mundo da leitura e da escrita, vão acumulando frustrações que os impedem de aprender, vão se tornando "indisponíveis para a aprendizagem". Cabe ressaltar que a maioria destes alunos percebe, às vezes com terrível clareza, que eles não estão aprendendo, ou seja, eles sabem que, ao aprová-los e fazê-los passar para uma classe mais avançada, a escola está, de certo modo, enganando-os.

\section{Escola: cenários de mudança}

Para que a escola venha a cumprir sua missão de democratizar o conhecimento e compensar as desigualdades sociais, será necessário investir na busca de novos modos de ensinar que considerem os novos modos de aprender que as crianças e jovens vêm desenvolvendo em decorrência das transformações sociais (Estatuto da Criança e do Adolescente) e técnicas (especialmente informática, robótica e redes telemáticas) e, muito especialmente, no contato com as tecnologias de informação e comunicação. Será preciso reinventar a pedagogia, incorporando estas tecnologias em projetos de aprendizagem inovadores. Vale repetir que a difusão das TIC em todas as esferas da sociedade tende a aprofundar as desigualdades sociais e a defasagem entre a escola e as crianças e adolescentes, cujas culturas e novas demandas a escola está ignorando. Ao desenvolver projetos educativos mais adequados, incorporando as TIC e incluindo aquelas crianças com dificuldades, de modo a assegurar-lhes aprendizagens significativas, a escola estará contribuindo para atenuar as desigualdades sociais e para minimizar o abismo existente entre uma 
cultura de elite amplamente "digitalizada" e uma nova "cultura do pobre", excluída da cultura letrada e dos novos saberes trazidos pelas novas tecnologias.

Seria preciso transformar as salas de aula em ambientes de estudo, ricos em recursos tecnológicos, e promover uma aprendizagem centrada no aluno e nas aprendizagens; na integração e interdisciplinaridade dos conteúdos e disciplinas; criar situações de interações colaborativas, combinando trabalho individualizado e em equipe, onde professores se transformem em mediadores do desenvolvimento de aprendizagens baseadas na pesquisa e os alunos construam de modo autônomo seus conhecimentos, pensamento crítico e capacidade de tomar decisões. Evidentemente, tal mudança de paradigma educacional implica que a formação de professores seja também transformada, passando de uma cultura de transmissão do conhecimento, centrada nos conteúdos e no professor, para uma cultura de compreensão e conhecimento dos sujeitos aprendentes, centrada nos processos de aprendizagem e nos modos de intervenção, para favorecer aprendizagens autônomas e colaborativas.

Cabe lembrar que, nas experiências observadas, os melhores resultados ocorrem na escola particular, onde existe um projeto pedagógico claramente estruturado e as condições de trabalho dos professores são melhores. A razão principal do sucesso, no entanto, decorre, sobretudo, do fato de que as crianças vêm de famílias favorecidas, com acesso não apenas às TIC, mas a outros bens de consumo, culturais ou não. Aqui se impõe lembrar uma triste evidência: quanto mais desfavorecidas as crianças e mais pobre a escola, mais dificuldades de concentração e de aprendizagem apresentam os alunos e piores são as condiçôes psicossociais e pedagógicas do trabalho docente e do processo de aprendizagem; e vice-versa: quanto mais favorecidas as crianças e melhores condições de trabalho oferece a escola, mais facilidades de concentração e aprendizagem apresentam os alunos. $\mathrm{Ou}$, ainda, dito de outra forma: as instâncias de socialização tendem a se reforçar mutuamente e, desse modo, atuam como fatores de reprodução e agravamento das desigualdades sociais.

As implicaçôes destas observações para o papel e a formação de professores são evidentes: o trabalho dos professores continua sendo fundamental e não pode ser substituído pelas máquinas. Porém, é indispensável que eles aprendam a lidar com a maior autonomia das crianças e a aceitar a hipótese da autodidaxia, além de aprender a usar as TIC em 
Infância, mídias e aprendizagem: autodidaxia e colaboração

suas práticas pedagógicas, é claro. Além de favorecer a aprendizagem colaborativa e cooperativa e desenvolver capacidades de autodidaxia, o uso pedagógico do computador estimula a motivação, desperta a curiosidade e favorece a concentração das crianças que, embora muito jovens, muitas vezes já têm experiência lúdica com estas máquinas e, para elas, seu uso na escola é desafiador e estimulante e lhes parece natural.

As concepções construtivistas do desenvolvimento intelectual da criança e dos processos de aprendizagem relacionados com as TIC deveriam levar a repensar a pedagogia e buscar um novo paradigma para a escola, no sentido de transformá-la efetivamente, tornando-a mais sintonizada com as novas gerações que já chegam à escola com muitas competências e grande familiaridade no uso de artefatos tecnológicos, tais como videogames, computadores, redes telemáticas, que propiciam oportunidades de informação, comunicação e interação, sem esquecer de que as crianças são usuários competentes e experimentados de televisão. O desafio da escola é o de potencializar as virtudes técnicas das TIC, colocando-as a serviço de aprendizagens significativas e nãoconvencionais, mais adequadas às culturas jovens e infantis. $\mathrm{O}$ que oferecem os videogames e a internet que a escola não oferece? Como podemos aprender com os aprendentes? Tais são as questões que devem orientar nossa reflexão na pesquisa e na formação de professores.

\section{Recebido e aprovado em agosto de 2008.}

\section{Notas}

1. As inferências e reflexôes aqui apresentadas se referem a resultados de cinco amplas pesquisas empíricas, todas apoiadas pelo CNPq, sobre o público infanto-juvenil das mídias: a primeira, realizada em Salvador, Bahia, em 1984, com 287 adolescentes, alunos de escolas públicas, buscou caracterizar o público desta faixa de idade; a segunda, realizada em Brasília, em 1987/88, com 497 jovens de 8 a 18 anos, de escolas públicas e privadas, estudou a programação televisual e buscou compreender as formas de apropriação e reelaboração das mensagens; a terceira, realizada em Florianópolis, em 1996, buscou estudar formas de uso pedagógico de mensagens televisuais na pré-escola (5/6 anos) e experiências de mídia-educação com adolescentes de 12 a 17 anos; a quarta, realizada em Florianópolis, em 2003, buscou caracterizar o público, o acesso e as formas de uso do computador e da internet entre adolescentes de 13 a 17 anos, alunos de escolas públicas e privadas. A última foi realizada em Florianópolis, em 2004/06 com crianças de 5 a 15 anos, sobre novos modos de aprendizagem com as TIC. Nas cinco pesquisas foram desenvolvidas metodologias quantitativas e qualitativas. Além dos relatórios de pesquisa 
apresentados ao CNPq e ao FUNCITEC/SC, relatos parciais estão disponíveis em nossas publicações e da equipe do Grupo de Pesquisa Comunic: <www.comunic.ufsc.br>.

2. Foram realizadas sete pesquisas empíricas de observação de projetos de aprendizagem com o uso das TIC, três delas incluindo crianças e adolescentes muito desfavorecidos ("em situação de risco"), duas outras trabalhando com alunos favorecidos de uma escola particular e as duas restantes com alunos de uma escola pública, pobres e de baixa classe média. $\mathrm{O}$ público estudado é formado de crianças e jovens estudantes do ensino regular, na faixa etária que vai dos 5 aos 15 anos, abrangendo alunos do ensino fundamental, de diferentes origens socioeconômicas e de grupos socioculturais diversos.

\section{Referências}

ALMEIDA, F.J. 500 anos de buscas sobre educação. In: FAZENDA, I. et al. Interdisciplinaridade e novas tecnologias. Campo Grande: UFMS, 1999.

ALMEIDA, F.J.; FONSECA JR., F.M. Projetos e ambientes inovadores. Brasília, DF: MEC/SEED, 2000.

ARENDT, H. La crise de la culture. Paris: Gallimard, 1972.

BABIN, P.; KOULOUMDJIAN, M.F. Os novos modos de compreender: a geração do áudio-visual e do computador. São Paulo: Paulinas, 1989.

BELlAN, C.; CHOMBART DE LAUWE, M.J. Enfants de l'image. Paris: Payot, 1979.

BELLONI, M.L. Crianças e mídias no Brasil: cenários de mudança. [s.n.t.]

BELLONI, M. L. A mundialização da cultura. Sociedade \& Estado, Brasília, DF, v. 9, n. 1/2, 1994.

BELlONI, M.L. O que é mídia-educação. Campinas: Autores Associados, 2001a.

BELLONI, M.L. A integração das TIC aos processos educacionais. In: Barreto, R.G. (Org.). Tecnologias educacionais e educação a distância: avaliando políticas e práticas. Rio de Janeiro: Quartet, $2001 \mathrm{~b}$.

BELLONI, M.L. (Org.). A formação na sociedade do espetáculo. São Paulo: Loyola, 2002. 
BELLONI, M.L. Infância, máquinas e violência. Educação \& Sociedade, Campinas, v. 25, n. 87, p. 575-598, maio/ago. 2004.

BELLONI, M.L. Infância, mídias e educação: revisitando o conceito de socialização. Perspectiva, Florianópolis, v. 25, n. 1, p. 57-82, 2007.

BELLONI, M.L. Os jovens e a internet: representações, usos e apropriações. In: Fantin, M.; Girardello, G. (Org.). Liga, roda, clica: estudos em mídia, cultura e infância. Campinas: Papirus, 2008.

BELLONI, M. L.; GOMES, N.G. Novas formas de aprender com as TIC. Florianópolis: UFSC; Funpesquisa, 2004. (Relatório de pesquisa).

BELLONI, M.L.; GOMES, N.G. Educação de jovens e as TIC: uma proposta de educação para jovens desfavorecidos. Trabalho apresentado no ENDIPE, 2004.

BELLONI, M.L. et al. Caracterização do público jovem das TIC $-1^{\mathrm{a}}$ fase. 2004. (Relatório final CNPq).

BELLONI, M.L.; GOMES, N.G.; CARRARO, D. As TIC como potencializadoras do processo de aprendizagem de jovens em situação de risco social. 2006. (Relatório de pesquisa FEPESC).

BELLONI, M.L.; GOMES, N.G.; CARRARO, D. As TIC na sala de aula: uma proposta para professores criativos. Florianópolis: [s.n], 2006.

BELLONI, M. L.; GOMES, N.G.; CARRARO, D. Caracterização do público jovem das TIC: autodidaxia e colaboração - 2a fase. 2007. (Relatório final CNPq).

BEVORT, E.; BRÉDA, I. Les jeunes et l'Internet. Paris: Clemi, 2001.

BOURDIEU, P. (Org.). La misère du monde. Paris: Seuil, 1993.

CASTRO, C.R.; MOURA, M.L.S.; RIBEIRO, A. A oficina de informática com meninos e meninas de rua. Psicologia \& Crítica, Porto Alegre, v. 12, n. 1, 1999.

DOISE, W. Quand les interactions sociales font progresser. In: DuRUBellat, M.; Fournier, M. L'intelligence de l'enfant: l'empreinte du social. Paris: Sciences Humaines, 2007. 
DURKHEIM, E. Education et sociologie. Paris: PUF, 1958.

FAGUNDES, L.C. et al. Aprendizes do futuro: as inovações começaram. In: CADERNOS Informática para a Mudança em Educação. Brasília, DF: MEC/SEED, 1999.

HERNANDEZ, F. Transgressão e mudança na educação. Porto Alegre: ARTMED, 1998.

LINARD, M. Autonomia do aprendente e as TIC. 2000. Disponível em: <http://www.comunic.ufsc.br> Acesso em: 17 jul. 2008.

MERLO FLORES, T. Investigación comparativa internacional "TV como te quiero". Trabalho apresentado na ANPEd, 2003.

MERLO FLORES, T. Hambre de inclusión y identidad. In: SEMINÁRIO "El impacto social de la imagen". Buenos Aires: Universidad de Buenos Aires, [s.d.].

MONTANDON, C. Sociologia da infância: balanço dos trabalhos em língua inglesa. Cadernos de Pesquisa, São Paulo, n. 112, p. 33-60, mar. 2001.

MONTANDON, C.; LONGCHAMP, P. L'expérience de l'autonomie chez l'enfant: une question récurrente dans la socialisation de l'enfant. Génève: Université de Génève, 2003. (Relatório de pesquisa)

MONTANDON, C.; LONGCHAMP, P. Você disse autonomia ?: uma breve percepção da experiência das crianças. Perspectiva, Florianópolis, v. 25, n. 1, p. 105-126, 2007.

PAPERT, Seymour. A máquina das crianças. Porto Alegre: ARTMED, 1994.

PERRIAULT, J. La logique de l'usage: essais sur les machines à communiquer. Paris: Flammarion, 1989.

PERRIAULT, J. La Communication du savoir à distance. Paris: L'Harmattan, 1996.

PERRIAULT, J. Éducation et nouvelles technologies. Paris: Nathan, 2002. PIAGET, J. La psychologie de l'intelligence. Paris: Colin,1968. 
PIAGET, J. Mes idées. Paris: Denoël-Gonthier, 1997.

SANTAROSA, L.M.C. Novos desafios para a educação na criação de ambientes de aprendizagem telemáticos. In: CONFERÊNCIA INTERNACIONAL DE TECNOLOGIAS DA INFORMAÇÃO E COMUNICAÇÃO - Challenges'99, 1., 1999, Braga. Anais... Braga, Universidade do Minho, 1999.

SARMENTO, M.J. A infância: paradigmas, correntes e perspectivas. Braga: IEC, 2000. (mimeo).

SIROTA, R. Emergência de uma sociologia da infância: evolução do objeto e do olhar. Cadernos de Pesquisa, São Paulo, n. 112, p. 7-31, mar. 2001.

TIJIBOY, A. et al. Aprendizagem cooperativa em ambiente telemáticos. Revista de Informática na Educação: Teoria e Prática, Porto Alegre, v. 1, n. 2, p. 19-28, 1999.

TURKLE, S. Les enfants de l'ordinateur. Paris: Denoël, 1984.

TURKLE, S. A vida no ecrã. Lisboa: Relógio d’Água, 1997.

VALENTE, J.A. Diferentes usos do computador na educação. In: VALENTE, J.A. Computadores e conhecimento: repensando a educação. Campinas: UNICAMP, 1993.

VALENTE, J.A. et al. O computador na sociedade do conhecimento. In: CADERNOS Informática para a Mudança em Educação. Brasília, DF: MEC/SEED, 1999.

VIGOTSKI, L.V. Pensamento e linguagem. São Paulo: Martins Fontes, 1987. 